\title{
TINDAK TUTUR ILOKUSI PENGAJAR PADA PROSES PEMBELAJARAN BAHASA MANDARIN
}

\author{
Monika Herliana*, M. Suryadi \\ Fakultas Ilmu Budaya, Universitas Diponegoro, Indonesia \\ *monika.herliana@nusantarun.com
}

DOI: 10.20884/1.jili.2019.10.2.2124

\begin{abstract}
Article History:
First Received:

ABSTRACT

$20 / 11 / 2019$

Final Revision:

The purpose of this study is to describe the illocutionary speech acts that

$13 / 12 / 2019$ contained in Mandarin language learning conducted by teachers. The approach used is a pragmatic approach, the theory by Searle. The research

Available online: data are the speeches of Mandarin Intermediate Conversation courses as many as two lecturers in the D3 Study Program of Mandarin in Jenderal

$30 / 12 / 2019$ Soedirman University. The data collection method uses observation and interviews with respondents. The analytical method used is the split method with the analysis technique that consisted of three activities, namely data reduction, data presentation, and drawing conclusions. The research findings contained 20 data consisting of assertive speech acts of 6 data, directive speech acts of 3 data, commissive speech acts of 7 data, expressive speech acts of 3 data, and declarative speech acts of 1 data. Speech data is delivered by instructors with 8 forms of Indonesian speech and 12 forms of Mandarin language. The dominance of teacher's utterances uses Mandarin can make learners get used to hearing and applying illocutionary speech with the correct Chinese rules and contexts.
\end{abstract}

Keywords: Illocutionary speech act; teacher; Mandarin language

\section{PENDAHULUAN}

Akhir-akhir ini perkembangan di berbagai bidang seperti bidang ekonomi Negara Tiongkok yang semakin pesat membuat kebutuhan bahasa Mandarin (selanjutnya disingkat BMn) semakin meningkat. Hal tersebut terjadi karena kebutuhan BMn sebagai sarana komunikasi semakin tinggi. Dengan melihat peluang itu, maka masyarakat berlomba untuk mempelajarai BMn untuk memenuhi kebutuhan pasar. Instansi pendidikan formal ataupun informal mulai banyak menyelenggarakan program studi bahasa Mandarin, termasuk Universitas Jenderal Soedirman Purwokerto (Unsoed).

Kajian tentang BMn saat ini semakin berkembang seiring dengan kebutuhan pengajaran BMn yang didasarkan pada penelitian (research based teaching). Pada proses pembelajaran, interaksi terjadi antara pengajar dan pemelajar karena kehidupan manusia tidak lepas dari 
interaksi sosial. Kelas merupakan salah satu tempat paling efektif yang digunakan oleh pengajar dan pemelajar melakukan interaksi untuk berbagi ilmu dan bertukar pendapat atau ide.

Universitas Jenderal Soedirman merupakan salah satu universitas yang memiliki program studi D3 bahasa Mandarin. Pada proses pembelajaran, pengajar program studi D3 bahasa Mandarin diharapkan menggunakan bahasa Mandarin sebagai bahasa utama saat pembelajaran berlangsung. Ketika proses pembelajaran berlangsung maka akan banyak terjadi interaksi antara pengajar dan pembelajar yang tidak luput dari bahasa sebagai salah satu alat komunikasi.

Proses pembelajaran bahasa Mandarin tidak pernah luput dari bahasa karena dalam interaksinya selalu mengandung berbagai macam tindak tutur yang dilakukan oleh pengajar ataupun oleh pembelajar. Pengajar menggunakan bahasa Mandarin sebagai bahasa utama untuk memberikan contoh kepada mahasiswanya agar selalu belajar berkomunikasi menggunakan bahasa Mandarin. Sedangkan penggunaan bahasa Mandarin oleh pemelajar merupakan sarana latihan agar dapat mengaplikasikan BMn dalam pembelajaran untuk agar terbiasa. Selain itu dapat membuat pemelajar terbiasa menggunakan BMn dengan lancar, serta sesuai dengan kaidah yang berlaku. Penggunaan bahasa Mandarin oleh pengajar menjadi sangat penting untuk mendukung perkembangan kemampuan BMn mahasiswa program studi D3 Bahasa Mandarin Unsoed. Berdasarkan hal tersebut, peneliti tertarik untuk mengkaji penggunaan bahasa yang digunakan oleh pengajar bahasa Mandarin sebagai percontohan untuk para pemelajar khususnya aspek berbicara.

Tindak tutur merupakan tindakan bertutur yang bertujuan untuk menyampaikan maksud dari pembicara kepada pendengar (Austin, 1962). Penyebutan tindak tutur tersebut berkaitan dengan kegiatan seseorang ketika bertutur untuk menyatakan sesuatu tersebut, maka dengan bertutur tersebut seseorang disebut dengan bertindak. Austin berpendapat bahawa tindak tutur dibedakan menjadi tiga, yaitu tindak tutur ilokusi, yaitu tindak tutur yang mengacu pada aktiviatas bertutur tanpa disertai tanggung jawab penuturnya untuk melakukan sesuatu tindakan tertentu. Contoh tindak tutur ilokusi antara lain adalah berjanji, membuat pernyataan, dan menyatakan perintah atau permintaan. Kedua, tindak tutur perlokusi, yaitu tindak tutur yang dapat memberikan pengaruh kepada pendengarnya. Sedangkan tindak tutur lokusi merupakan pernyataan seseorang yang hanya memberikan informasi tanpa adanya keinginan timbal balik dari mitra tutur kepada penutur.

Pendapat Austin tentang munculnya jenis-jenis tindak tutur ilokusi adalah karena adanya interaksi penutur dan mitra tutur yang secara timbal balik saling berbagi informasi, yakni penutur bisa menjadi mitra tutur dan mitra tutur dapat menjadi penutur. Austin dan Searle sama-sama menelaaah tindak tutur dari segi penutur (hal yang dipikirkan oleh penutur). Jenis tindak tutur 
dalam pragmatik (Searle, 1971) ada lima, yaitu: a) Representatif atau Asertif, merupakan tindak tutur yang menyatakan kebenaran dari sebuah tuturan yang berfungsi memberi informasi kepada pendengar. Tindak tutur representatif ini dapat berupa mempertahankan, meminta, mengatakan, menyatakan dan melaporkan. b) Direktif, merupakan tindak tutur yang bertujuan agar mitra tutur pendengar melakukan sesuatu kepada penutur. Dari pengertian tersebut dapat disimpulkan bahwa pada dasarnya tindak tutur direktif adalah tindak tutur yang berupa kalimat perintah, yaitu penutur mengharapkan mitra tutur melakukan sesuatu kepada penutur. Tindak tutur direktif ini dapat berupa: meminta, memerintah, menasihati, memesan, dan merekomendasi. c) Komisif, yaitu tindak tutur berupa komitmen atau melakukan sesuatu terhadap apa yang telah dituturkan. Dalam hal ini, si pembicara akan melakukan sesuatu di masa mendatang setelah menyampaikan ujarannya. Pendapat Mey (1993:164) tentang tindak tutur komisif adalah sebagai berikut: "commissives operate a change in the world by means of creating an obligation; however, this obligation is created in the speaker, not in the hearer". Kesimpulannya, tindak tutur komisif merupakan keharusan dalam melakukan sesuatu yang dibebankan kepada penutur bukan mitar tutur. Tindak tutur komisif biasanya dinyatakan dengan kalimat perintah, pertanyaan, pernyataan, atau melalui pernyataan langsung berdasarkan fungsinya. Sedangkan kata kerja dalam tindak komisif terdapat pada kata kerja berupa setuju, berjanji, bersumpah, menolak, dan lainnya. d) Ekspresif, merupakan tindak tutur yang mengekspresikan keadaan seseorang, baik senang, sedih, kecewa, bangga, dan lain sebagainya. Tindak tutur ekspresif muncul karena adanya tindak tutur sebelumnya yang mengakibatkan munculnya berbagai macam ekspresi tersebut. Contoh dari tindak tutur ekspresif adalah permintaan maaf, penyesalan dan ungkapan terima kasih. e) Deklarasi, merupakan tindak tutur yang berupa tindakan mempengaruhi kondisi seseorang. Pengertian lain yaitu adalah ilokusi yang bila performansinya berhasil akan menyebabkan korespondensi yang baik antara isi proposisional dengan realitas. Sebuah ujaran bisa saja berfungsi lebih dari satu karena keberhasilan dari sebuah ujaran sangat tergantung kepada kondisi kontekstual di mana ujaran tersebut dituturkan (Megawati, 2016).

Setelah mengetahui jenis-jenis tindak tutur, berikut ini juga terdpat beberapa fungsi dari tindak tutur itu sendiri. Menurut Van Ek (Jumadi, 2010) dalam Isnaniah menyatakan enam fungsi tindak tutur sebagai berikut: a) Untuk tukar menukar informasi faktual, misalnya untuk mengidentifikasi bertanya, melaporkan dan mengatakan. b) Mengungkapkan informasi intelektual, misalnya setuju/tidak setuju, tahu/tidak tahu, dan ingat/ tidak ingat. c) Mengungkapkan sikap emosi misalnya berminat/kurang berminat, heran atau tidak heran, takut, cemas, dan simpati. d) Mengungkapkan sikap moral, misalnya meminta maaf/memberi maaf, 
setuju/tidak setuju, menyesal dan acuh. e) Meyakinkan/mempengaruhi, misalnya menyarankan, menasehati, dan memberikan peringatan. f) Sosialisasi, misalnya memperkenalkan, menarik perhatian dan menyapa.

Tujuan penelitian ini adalah mendeskripsikan bentuk tindak tutur ilokusi bahasa Indonesia dan bahasa Mandarin yang dilakukan oleh pengajar selama proses pembelajaran berlangsung pada program studi D3 Bahasa Mandarin Unsoed Purwokerto.

\section{METODE PENELITIAN}

Jenis penelitian yang digunakan adalah penelitian deskriptif kualitatif karena data yang dihasilkan berupa kata-kata dan bukan berupa angka (Moleong, 2010). Penelitian dilakukan selama bulan Januari-Juni 2019. Data merupakan tuturan lisan pengajar beserta konteksnya selama pembelajaran mata kuliah Percakapan Mandarin Menengah di dalam kelas pada prodi D3 Bahasa Mandarin Unsoed. Peneliti menghimpun data dengan melakukan wawancara dan observasi terhadap responden yaitu pengajar mata kuliah Percakapan Mandarin menengah sebanyak dua orang pengajar. Peneliti memilih tuturan pengajar karena setelah melakukan dan mengidentifikasi jenis tindak tutur ilokusi pada pengajar maka dapat dijadikan sebagai bahan evaluasi pengajar. Evaluasi berupa tepat atau tidaknya konteks tuturan yang dilakukan oleh pengajar dan dijadikan sebagai percontohan untuk pemelajar

Metode penyediaan dilakukan dengan metode observasi, yaitu metode yang digunakan untuk memperoleh data dengan mengikuti proses pembelajaran di kelas (Muhammad, 2014). Dalam hal ini, pembelajaran kelas yang dimaksud adalah kelas pembelajaran BMn. Serta melakukan wawancara dengan pengajar mata kuliah terkait. Sedangkan teknik lanjutan yang digunakan oleh peneliti adalah teknik sadap, teknik simak libat cakap, dan teknik catat (Mahsun, 2007).

Analisis data adalah kegiatan mengurutkan, mengorganisasikan, mengelompokkan data sesuai dengan kategori dan satuannya, tujuan analisis data adalah menemukan kaidah-kaidah atau atauran-aturan dalam bertutur (Muhammad, 2014). Metode yang digunakan dalam analisis data adalah metode agih. Sudaryanto (2015:9) mengungkapkan bahwa alat penentu merupakan bagian dari bahasa itu sendiri atau berupa unsur dari bahasa objek sasaran penelitian itu sendiri. Analisis dilakukan berdasarkan lima jenis tindak tutur ilokusi menurut Searle (1971). Teknik analisis data pada penelitian ini terdiri atas tiga kegiatan, yaitu reduksi data, penyajian data, dan penarikan kesimpulan. Data disajikan dalam bentuk informal, yaitu penyajian data menggunakan kata-kata bias untuk merumuskan kaidah-kaidah sesuai dengan ranahnya berdasarkan teori tindak tutur Searle (Sudaryanto, 2015). 


\section{HASIL DAN PEMBAHASAN}

\section{Tindak Tutur Ilokusi Interaksi Pengajar di Prodi D3 Bahasa Mandarin Unsoed}

Hasil dan pembahasan penelitian ini berkaitan dengan tindak tutur ilokusi tuturan pengajar yang terdapat dalam interaksi pembelajaran antara pengajar dan pemelajar. Pada bagian hasil dan pembahasan diuraikan hasil penelitian yang mengemukakan tentang jenis tindak tutur yang muncul pada tuturan pengajar adalah jenis representatif atau asertif, direktif, komisif, ekspresif, dan deklaratif sebanyak 20 tuturan. Jenis tuturan yang terdapat dalam penelitian ini, diuraikan dalam analisis berikut ini.

Tabel 1. Hasil Analisis Tindak Tutur Ilokusi

\begin{tabular}{|c|c|c|c|}
\hline No & Dialog & $\begin{array}{c}\text { Tindak } \\
\text { tutur }\end{array}$ & Analisis \\
\hline 1 & $\begin{array}{l}\text { Pengajar : "Wo kan. O dui le. Letaknya } \\
\text { sudah tepat sebagai kata satuan untuk baju", } \\
\text { (Saya lihat. O ini sudah beetul. Letaknya sudah } \\
\text { tepat sebagai kata satuan untuk baju) } \\
\text { Pemelajar : "Xie xie ni" } \\
\text { (Terima kasih bu) }\end{array}$ & Asertif & $\begin{array}{l}\text { asertif, } \\
\text { pemberian } \\
\text { informasi oleh } \\
\text { pengajar }\end{array}$ \\
\hline 2 & $\begin{array}{l}\text { Pemelajar: "Laoshi, minggu depan materi dikte } \\
\text { bab berapa?". (Bu, minggu depan materi dikte } \\
\text { bab berapa?) } \\
\text { Pengajar: "ehm ya bab 5". }\end{array}$ & Asertif & $\begin{array}{l}\text { Asertif, } \\
\text { pemberian } \\
\text { informasi oleh } \\
\text { pengajar }\end{array}$ \\
\hline 3 & $\begin{array}{l}\text { Pengajar: "Aliev, bang wo na wo de shu". } \\
\text { (Aliev, tolong ambilkan buku saya) } \\
\text { Pemelajar :hao de (baik bu) }\end{array}$ & Direktif & $\begin{array}{l}\text { Direktif, jenis } \\
\text { permintaan } \\
\text { oleh pengajar. }\end{array}$ \\
\hline 4 & $\begin{array}{l}\text { Pengajar : "haha wo bu xihuan horror, } \\
\text { kalau ada film romance, kita nonton bareng } \\
\text { ya" (haha saya tidak suka nonton horror, kalau } \\
\text { ada film romantis, kita nonton ya) } \\
\text { Pemelajar :"Wah asik." (Wah, asik) }\end{array}$ & Komisif & $\begin{array}{l}\text { Komisif, jenis } \\
\text { penawaran oleh } \\
\text { pengajar }\end{array}$ \\
\hline
\end{tabular}




\begin{tabular}{|c|c|c|c|}
\hline 5 & $\begin{array}{l}\text { Pengajar : "Shuo dao dianying, zai } \\
\text { bioskop you shenme haokan de dianying } \\
\text { ne?women yiqi kan ba." (Berbicara tentang } \\
\text { film, di bioskop ada film apa yang bagus?) } \\
\text { Pemelajar : "film horror laoshi, jangan } \\
\text { nonton, nakutin" (Film horror laoshi, jangan } \\
\text { nonton, menakutkan) }\end{array}$ & Komisif & $\begin{array}{l}\text { Komisif, jenis } \\
\text { pernyataan oleh } \\
\text { pemelajar }\end{array}$ \\
\hline 6 & $\begin{array}{l}\text { Pemelajar : "Kami mengerjakan yang } \\
\text { nomor berapa lagi laoshi?" (bu, kami } \\
\text { mengerjakan yang nomor berapa lagi?) } \\
\text { Pengajar : "Xianzai nimen huida di si } \\
\text { hao" (Sekarang kalian menjawab nomor empat) }\end{array}$ & Direktif & $\begin{array}{c}\text { Direktif } \\
\text { memerintah } \\
\text { oleh pengajar }\end{array}$ \\
\hline 7 & $\begin{array}{l}\text { Pengajar : “Jie xi alai, women kan } \\
\text { xiamian de tu pian." (selanjutnya, kita melihat } \\
\text { gambar yang selanjutnya) } \\
\text { Pemelajar : "halaman berapa laoshi?" } \\
\text { (halaman berapa laoshi) } \\
\text { Pengajar : "di sanshi wu ye" (halaman } \\
\text { tiga puluh lima) }\end{array}$ & Komisif & $\begin{array}{l}\text { Komisif, jenis } \\
\text { perintah oleh } \\
\text { pengaja }\end{array}$ \\
\hline 8 & $\begin{array}{l}\text { Pemelajar : "Laoshi deng yi xia" (tunggu } \\
\text { sebentar bu) } \\
\text { Pengajar: "Kuai yi dian, kuai yao xia ke le" } \\
\text { (Cepat sedikit, sudah akan selesai perkuliahan) }\end{array}$ & Asertif & $\begin{array}{l}\text { asertif, } \\
\text { pemberian } \\
\text { informasi oleh } \\
\text { pengajar }\end{array}$ \\
\hline 9 & $\begin{array}{l}\text { Pengajar : “jintian Chandra bu lai } \\
\text { shangke yin wei sheng bing, shi ba. (hari ini } \\
\text { Chandra tidak masuk karena sakit, betul?) }\end{array}$ & Direktif & $\begin{array}{c}\text { Direktif, } \\
\text { perduli } \\
\text { terhadap } \\
\text { pemelajar } \\
\end{array}$ \\
\hline 10 & $\begin{array}{l}\text { Pemelajar: "PR nya banyak banget laoshi".(Bu, } \\
\text { PR nya banyak sekali) } \\
\text { Pengajar: "Ya kalau selesai semua, laoshi } \\
\text { kasih A lah". (Ya kalau selesai semua saya beri } \\
\text { nilai A lah) }\end{array}$ & Komisif & $\begin{array}{l}\text { Komisif, jenis } \\
\text { janji yang } \\
\text { dilakukan oleh } \\
\text { pengajar }\end{array}$ \\
\hline 11 & $\begin{array}{l}\text { Pemelajar: “... bagaimana kalau besok kita } \\
\text { kuliah dua sks sekalian, kan pelajaran Pak } \\
\text { Bagus kosong." } \\
\text { Pengajar :’Wah dangran keyi."(Wah tentu } \\
\text { saja boleh) }\end{array}$ & Komisif & $\begin{array}{l}\text { Komisif, jenis } \\
\text { pernyataan } \\
\text { setuju dari } \\
\text { pengajar }\end{array}$ \\
\hline
\end{tabular}




\begin{tabular}{|c|c|c|c|}
\hline 12 & $\begin{array}{l}\text { Pemelajar : “...dikerjakan di kertaas laoshi?” } \\
\text { (dikerjakan di kertas bu?) } \\
\text { Pengajar : "shi”'(iya) }\end{array}$ & Asertif & $\begin{array}{l}\text { asertif, } \\
\text { pemberian } \\
\text { informasi oleh } \\
\text { pengajar }\end{array}$ \\
\hline 13 & $\begin{array}{l}\text { Pengajar: "Jintian lai de ren hen shao"(hari } \\
\text { ini siswa yang datang tidak banyak ya) }\end{array}$ & Komisif & $\begin{array}{l}\text { Komisif, jenis } \\
\text { pernyataan oleh } \\
\text { pengajar }\end{array}$ \\
\hline 14 & $\begin{array}{l}\text { Pengajar : "bu hao yisi, laoshi lupa tutup } \\
\text { pintunya. Awal, neng bang wo guan men } \\
\text { ma?." (Maaf, ibu lupa menutup pintunya, Awal, } \\
\text { bisa bantu ibu menutup pintu?) } \\
\text { Pemelajar : "Hao laoshi" (Baik bu) }\end{array}$ & Ekspresif & $\begin{array}{l}\text { Ekspresif, oleh } \\
\text { pengajar }\end{array}$ \\
\hline 15 & $\begin{array}{l}\text { Pengajar: "Bagaimana kalau satu kelompok } \\
\text { tiga orang saja? Cukup kan?” } \\
\text { Pemelajar : “cukup laoshi”. (cukup bu) }\end{array}$ & Komisif & $\begin{array}{l}\text { Komisif, jenis } \\
\text { penawaran oleh } \\
\text { pengajar }\end{array}$ \\
\hline 16 & $\begin{array}{l}\text { Pemelajar : “... kalau di Zhong Guo } \\
\text { barangnya murah-murah ya laoshi?” (...kalau } \\
\text { di Tiongkok barangnya murah-murah ya bu?) } \\
\text { Pengajar : “Ya jelas murah, hen pian yi. } \\
\text { Seringnya ada dazhe, diskon.” (Ya jelas murah, } \\
\text { sangat murah. Seringnya ada potongan harga, } \\
\text { diskon.) }\end{array}$ & Asertif & $\begin{array}{l}\text { Asertif jenis } \\
\text { melaporkan } \\
\text { oleh pengajar }\end{array}$ \\
\hline 17 & $\begin{array}{l}\text { Pengajar : "Ya makanya kalian bisa cari } \\
\text { jiang xue jin biar bisa ke Zhong Guo." (Ya } \\
\text { makanya kalian bisa cari beasiswa biar bisa ke } \\
\text { Tiongkok) }\end{array}$ & Deklaratif & $\begin{array}{l}\text { Deklaratif jenis } \\
\text { perintah oleh } \\
\text { pengajar }\end{array}$ \\
\hline 18 & $\begin{array}{l}\text { Pemelajar : “... hari ini nggak ada tingxie } \\
\text { laoshi, berarti buka bab baru ya?" (...hari ini } \\
\text { tidak ada dikte ya bu, berarti buka bab baru ya?) } \\
\text { Pengajar : "Shei shuo mei tingxie? Setiap } \\
\text { minggu pasti ada, kok enak men.” (Siapa yang } \\
\text { mengatakan tidak ada dikte, kok enak sekali) }\end{array}$ & Asertif & $\begin{array}{l}\text { Asertif, } \\
\text { pernyataan oleh } \\
\text { pengajar }\end{array}$ \\
\hline 19 & $\begin{array}{l}\text { Pemelajar: "Ini laoshi absensinya." (ini bu } \\
\text { absensinya) } \\
\text { Pengajar:"haode, xiexie ni." (ok, terima kasih) }\end{array}$ & Ekspresif & $\begin{array}{l}\text { Ekspresif, } \\
\text { ungkapan } \\
\text { terimakasih } \\
\text { oleh pengajar }\end{array}$ \\
\hline
\end{tabular}




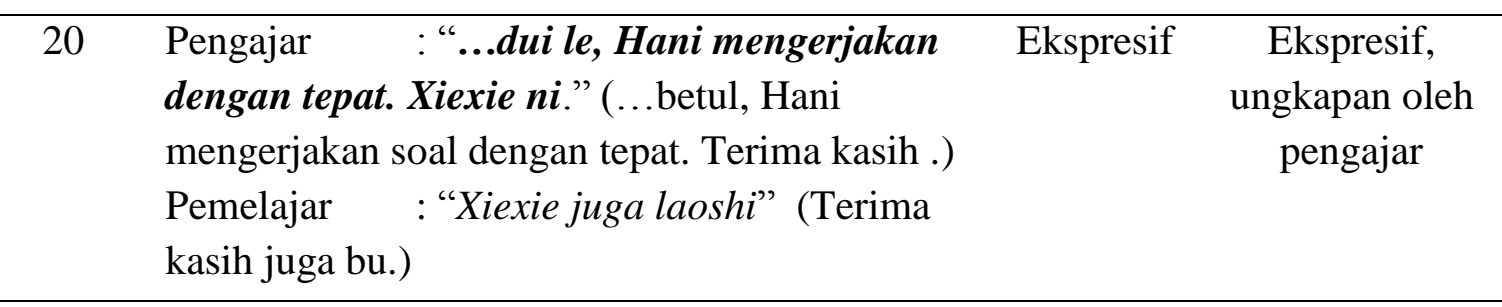

Klasifikasi tindak tutur ilokusi berdasarkan teori Searle terdapat dalam analisis berikut ini.

\section{Tindak Tutur Asertif}

Pada peristiwa tutur yang terjadi dalam pembelajaran, jenis tindak tutur asertif menekankan bahwa fungsi tuturan terdapat pada nilai-nilai kebenaran dari sebuah ujaran. Dalam mengungkapkan maksud dari pembicara menggunakan bahasa untuk menyatakan apa yang mereka ketahui.

\section{Data 1 \\ Pemelajar : :Laoshi, kalau huruf 'jian' diletakkan disini dui bu dui?." \\ (Bu, kalau huruf 'le' diletakkan disini betul tidak?) \\ Pengajar : : "Wo kan. O dui le. Letaknya sudah tepat sebagai kata satuan untuk baju” (Saya lihat. O ini sudah beetul. Letaknya sudah tepat sebagai kata satuan untuk baju) \\ Pemelajar : "Xie xie ni" \\ (Terima kasih bu) \\ Konteks sosiokultural: \\ Percakapan terjadi pada mata kuliah Percakapan Mandarin Menengah, tema 3 'Ni Mai Shen Me Dong xi' 'Apa barang yang kamu beli?'. Tuturan terjadi antara pengejar dan pemelajar, bahasa yang digunakan adalah bahasa Mandarin dan bahasa Indonesia pada saat pengajar menjelaskan kosakata dan kemudian pemelajar membuat contoh kalimat menggunakan kosakata yang sedang dijelaskan.}

Pada data 1-T1 pemelajar sedang bertanya kepada pengajar tentang posisi salah satu kosakata dalam kaidah tata bahasa bahasa Mandarin (selanjutnya disingkat BM). Pertanyaan diutarakan oleh pemelajar dan kemudian pengajarr memberikan jawaban atas pertanyaan tersebut sebagai tindak tutur ilokusi. Berdasarkan informasi yang dituturkan oleh pengajar 'Wo kan. O dui le. Letaknya sudah tepat sebagai kata satuan untuk baju' (Saya lihat. O ini sudah beetul. Letaknya sudah tepat sebagai kata satuan untuk baju), maka pemelajar memahami bahwa tuturan yang diungkapkan oleh pengajar memiliki unsur informasi mengenai kaidah penggunaan dan letak kosakata 'jian' (lembar) yang tepat. Pemelajar memahami bahwa pengejar menggunaka tindak tutur asertif untuk menjelaskan kaidah yang sesuai, sehingga respon yang muncul dari pengajar adalah mengerti bagaimana menggunakan kata satuan 'jian' secara tepat.

Peristiwa tutur yang terjadi berkaitan denga jenis tindak tutur asertif tidak hanya berkaitan dengan kaidah BM. Berikutnya, terdapat juga jenis tindak tutur asertif pada data berikut ini. 


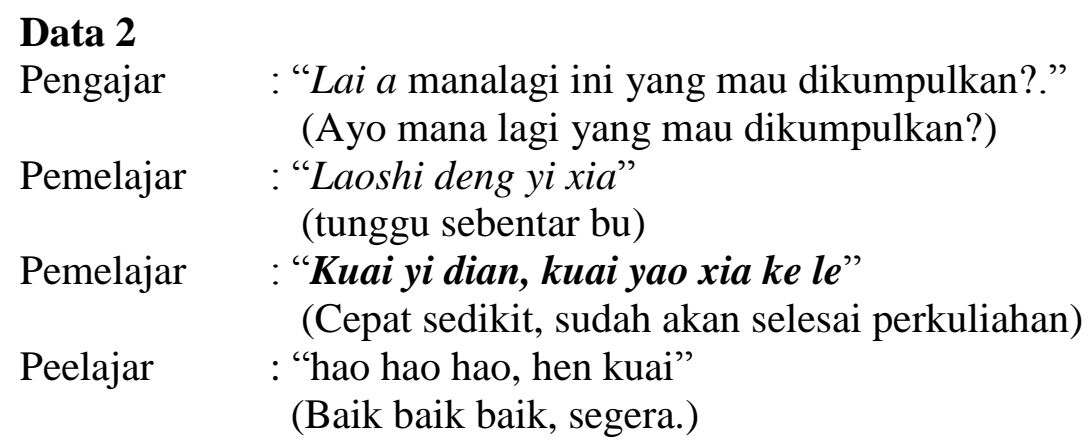

\section{Konteks sosiokultural:}

Percakapan terjadi pada mata kuliah Percakapan Mandarin Menengah, tema 5 'Dong wu yuan Zen Me Zou?' 'Bagaimana pergi ke Kebun Binatang?'. Tuturan terjadi antara pengajar dan pemelajar, bahasa yang digunakan adalah bahasa Mandarin dan bahasa Indonesia pada saat pengajar selesai memberikan tugas, dan memberikan perintah kepada pemelajar untuk menulis paragraf pendek yang sesuai dengan tema.

Pada data 2-T2 menunjukkan bahwa tuturan terjadi pada saat pembelajaran bahasa mandarin di dalam kelas. Tuturan terjadi antara pengajar dan pemelajar pada saat akhir perkuliahan. Sebuah pernyataan dituturkan oleh pengajar untuk mendesak pemelajar segera mengumpulkan tugas. Tuturan pengajar "Kuai yi dian, kuai yao xia ke le" (Cepat sedikit, sudah akan selesai perkuliahan), merupakan kalimat pernyataan yang memberikan informasi kepada pemelajar yang masih mengerjakan tugas walaupun waktu sudah habis agar lekas menyelesaikan tugas karena waktu akan segera habis. Pemelajar memahami tuturan tersebut dan segera menyelesaikan tugas karena pengajar menggunakan tindak tutur asertif yang mengandung informasi bahwa waktu mengerjakan tugas akan segera berakhir.

Dari sebanyak 20 tuturan pengajar, ditemukan sebanyak 6 tindak tutur jenis asertif yang terbagi ke dalam tiga tuturan asertif yang berbahasa Indonesia dan tiga tuturan berbahasa Mandarin.

\section{Tindak Tutur Direktif}

Tindak tutur direktif merupakan jenis tindak tutur yang memiliki bentuk kalimat perintah untuk menuntut orang lain melakukan sesuatu. Tindak tutur ini diungkapkan oleh penutur agar mitra tutur melakukan sesuatu. Tindak tutur dapat berupa meminta, memerintah, atau menasehati.

\section{Data 3}

Pengajar : "Jintian you zuo ye ma?." (apakah hari ini ada tugas?)

Pemelajar : "You a Laoshi" (Ada Bu) 


\begin{tabular}{|c|c|}
\hline Pemelajar & $\begin{array}{l}\text { : “Na xianzai jiu jiao gei laoshi” } \\
\text { (Ya sekarang dikumpulkan) }\end{array}$ \\
\hline Pemelajar & $\begin{array}{l}\text { :"Belum selesai laoshi, zenmeban ne, zao gao!" } \\
\text { (Belum selesai bu, bagaimana ini, gawat!) }\end{array}$ \\
\hline
\end{tabular}

\section{Konteks sosiokultural:}

Percakapan terjadi pada mata kuliah Percakapan Mandarin Menengah, tema 6 'Ni yao bu yao dang wo de fudao laoshi?' (Apakah kamu mau menjadi guru bimbinganku?). Tuturan terjadi antara pengajar dan pemelajar, bahasa yang digunakan adalah bahasa Mandarin dan bahasa Indonesia. Pengajar sebelum mulai memberikan materi pembelajaran, pengajar menanyakan tugas dan memberikan perintah mengumpulkan tugas tersebut.

Data 3-T3 memperlihatkan bahwa peristiwa tutur terjadi antara pengajar dan pemelajar dengan menggunakan dua jenis bahasa, yaitu bahasa Indonesia (BI) dan bahasa Mandarin (BM). tuturan yang terjadi pada saat sebelum perkuliahan dimualai menunjukkan bahwa pengajar mengajukan pertanyaan terlebih dahulu kepada pemelajar. Setelah itu, pemelajar memberikan respon berupa jawaban tentang tugas. Setelah mendapatkan respon dari pemelajar, Pengajar mengeluarkan tuturan perintah "Na xianzai jiu jiao gei laoshi" (Ya sekarang dikumpulkan), dengan maksud agar pemelajar memberikan tugas yang sudah dikerjakan dan memberikan kepada pengajar. Pemelajar memahami bahwa pengajar menggunakan jenis tindak tutur Direktif sehingga respon yang muncul adalah jawaban dari mahasiswa "Belum selesai laoshi, zenmeban ne, zao gao!” (Belum selesai bu, bagaimana ini, gawat!) yang memiliki maksud tuturan bahwa tugas belum selesai dikumpulkan dan terpaksa memberikan kepada pengajar.

Jenis tindak tutur direktif berupa perintah juga terdapat pada data berikut ini.

\section{Data 4}

\begin{tabular}{|c|c|}
\hline Pemelajar & $\begin{array}{l}\text { "Kami mengerjakan yang nomor berapa lagi laoshi?" } \\
\text { (bu, kami mengerjakan yang nomor berapa lagi?) }\end{array}$ \\
\hline Pengajar & $\begin{array}{l}\text { : "Xianzai nimen huida di si hao" } \\
\text { (Sekarang kalian menjawab nomor empat) }\end{array}$ \\
\hline Pemelajar & $\begin{array}{l}\text { :"Itu giliran Wiwit laoshi" } \\
\text { (Bu, itu giliran Wiwit.) }\end{array}$ \\
\hline Pengajar & $\begin{array}{l}\text { : "Hao de. Sekarang Wiwit." } \\
\text { (Baiklah, sekarang Wiwit.) }\end{array}$ \\
\hline
\end{tabular}

\section{Konteks sosiokultural:}

Percakapan terjadi pada mata kuliah Percakapan Mandarin Menengah, tema 6 ' $N i$ yao bu yao dang wo de fudao laoshi?' (Apakah kamu mau menjadi guru bimbinganku?). Tuturan terjadi antara pengajar dan pemelajar, bahasa yang digunakan adalah bahasa Mandarin dan bahasa Indonesia. Pengajar sebelum mulai memberikan materi pembelajaran, pengajar menanyakan tugas dan memberikan perintah mengumpulkan tugas tersebut.

Data 4-T4 merupakan percakapan antara pengajar dan pemelajar yang menggunakan dua jenis bahasa yaitu BI dan BM dalam tuturannya. pada saat pembelajaran terdapat sesi 
mengerjakan tugas individu secara bergantian. Pada data 4-T4 terdapat tuturan yang disampaikan oleh pengajar "Xianzai nimen huida di si hao" (Sekarang kalian menjawab nomor empat) yang mengandung unsur perintah. Berdasarkan informasi yang terdapat dalam tuturan, pengajar menuntut pemelajar untuk menjawab pertanyaan nomor empat. Pemelajar memahami tuturan jenis direktif yang diampaikan oleh pengajar, oleh karena itu pemelajar kemudian memberikan respon dengan menjawab siapa yang seharusnya mengerjakan tugas tersebut. Dari sebanyak 20 tuturan pengajar, ditemukan sebanyak 3 tindak tutur jenis direktif yang ketiganya menggunakan BMn dengan kaidah dan konteks BMn yang sesuai.

\section{Tindak Tutur Komisif}

Peristiwa tutur yang terjadi saat pembelajaran juga memiliki maksud dan tujuan penuturnya. Jenis yang dimaksud adalah tuturan yang membuat pembicara berkomitmen terhadap rencana yang dibuatnya. Dengan kata lain bahwa penutur dan dapat mempengaruhi lawan tutur untuk melakukan sesuatu dimasa mendatang yang sesuai dengan tuturan.

\section{Data 5}

Pemelajar : "Women dou hen xihuan kan dianying." (kami semua sangat suka menonton film)

Pengajar : "Shuo dao dianying, zai bioskop you shenme haokan de dianying ne?" (Berbicara tentang film, di bioskop ada film apa yang bagus?)

Pemelajar : "film horror laoshi, jangan nonton, nakutin" (Film horror laoshi, jangan nonton, menakutkan)

\section{Pengajar : : "haha wo bu xihuan horror, kalau ada film romance, kita nonton bareng} ya"

(haha sy tidak suka nonton horror, kalau ada film romantis, kita nonton ya)

Pemelajar :"Wah asik."

(Wah, asik)

\section{Konteks sosiokultural:}

Percakapan terjadi pada mata kuliah Percakapan Mandarin Menengah, tema 4 'Kan Dianying shi Yi Zhong Xiang Shou' (Menonton Film Adalah Kegemaranku). Tuturan terjadi antara pengajar dan pemelajar, bahasa yang digunakan adalah bahasa Mandarin dan bahasa Indonesia. Pengajar sebelum mulai memberikan materi pembelajaran, pengajar menanyakan pengalaman pribadi tentang film kepada pemelajar.

Data 5-T5 memperlihatkan bahwa tuturan terjadi antara pengajar dan pemelajar dalam situasi formal pembelajaran bahasa Mandarin. Bahasa yang digunakan dalam tutura tersebur adalah BI dan BM. pada peristiwa tutur tersebut, tuturan disampaikan pada saat pengajar akan memulai pembelajaran dengan menanyakan pengalaman pemelajar yang terkait dengan tema film. Dalam percakapan tersebut, tuturan pengajar "haha wo bu xihuan horror, kalau ada film 
romance, kita nonton bareng ya" (haha sy tidak suka nonton horror, kalau ada film romantis, kita nonton ya) merupakan jenis tindak tutur ilokusi berupa janji menonton film bersama-sama di bioskop. Pernyataan tersebut mendapatkan respon dari pemelajar dengan tuturan "Wah asik." yang mengekspresikan bahwa mereka sangat senang walaupun tuturan pengajar belum terjadi.

Selanjutnya tindak tutur ilokusi tuturan pengajar juga terdapat pada tuturan berikut. Pengajar dan pemelajar melakukan percakapan pada saat membicarakan tema perkuliahan.

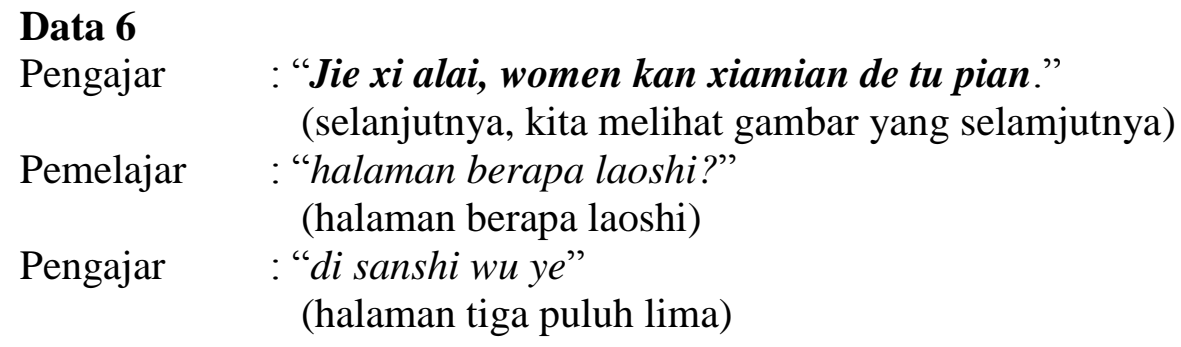

\section{Konteks sosiokultural:}

Percakapan terjadi pada mata kuliah Percakapan Mandarin Menengah, tema 6 'Ni yao bu yao dang wo de fudao laoshi?' (Apakah kamu mau menjadi guru bimbinganku?). Tuturan terjadi antara pengajar dan pemelajar, bahasa yang digunakan adalah bahasa Mandarin dan bahasa Indonesia. Pengajar memberikan perintah pada saat menjelaskan materi pembelajaran.

Data 6-T6 memperlihatkan bahwa dalam tuturan pengajar terdapat jenis tindak tutur ilokusi. Hal tersebut terdapat dalam tuturan pengajar "Jie xi alai, women kan xiamian de tu pian." (selanjutnya, kita melihat gambar yang selamjutnya). Tuturan tersebut disampaikan oleh pengajar tindak tutur berupa penutur maupun lawan tutur mampu berkomitmen untuk trncana yang dibuat, yaitu dalam tuturannya untuk melihat gambar selanjutnya. Respon yang diberikan oleh pemelajar dengan tuturan "halaman berapa laoshi?" yang menayakan halaman yang dimaksud pengajar, dan kemudian mereka bersama membahas materi selanjutnya dengan membuaka halaman baru. Dengan demikian jenis tindak tutur ilokusi terdapat pada tuturan pengajar dan membuat penutur maupun lawan tuturnya untuk melakukan sesuatu sesuai dengan tuturan.

Dari sebanyak 20 tuturan pengajar, ditemukan sebanyak 7 tindak tutur jenis komisif yang terbagi ke dalam empat tindak tutur komisif yang berbahasa Indonesia dan tiga tuturan berbahasa Mandarin.

\section{Tindak Tutur Ekspresif}

Pada umumya, jenis tindak tutur ekspresif yang terdapat dalam tuturan merupakan merupakan tuturan yang muncul sebagai tindakan lanjutan dari tindakan sebelumnya. Tindak 
tutur ini pada umumnya merupakan tindakan yang mengekspresikan tentang keadaan psikologis dari penutur.

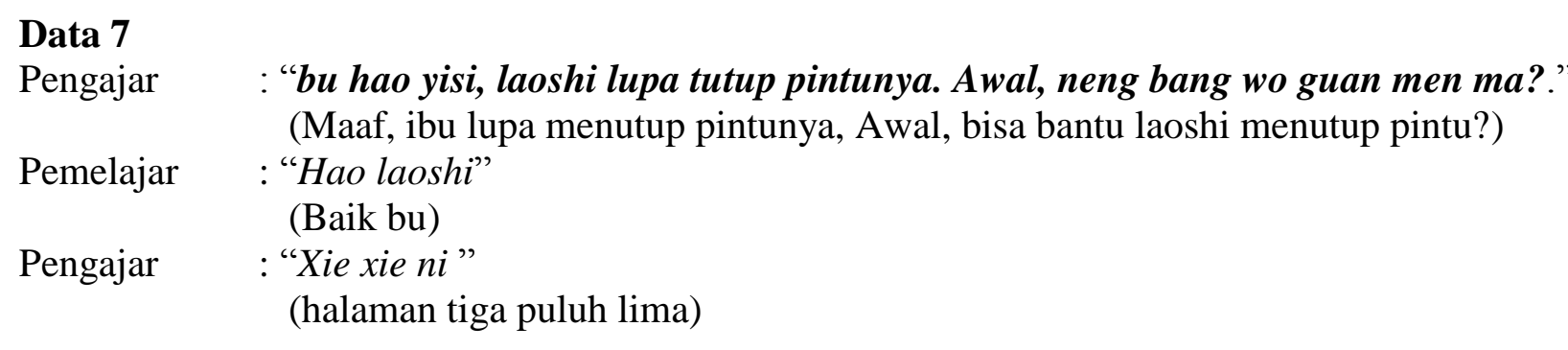

\section{Konteks sosiokultural:}

Percakapan terjadi pada mata kuliah Percakapan Mandarin Menengah, tema 6 'Ni yao bu yao dang wo de fudao laoshi?' (Apakah kamu mau menjadi guru bimbinganku?). Tuturan terjadi antara pengajar dan pemelajar, bahasa yang digunakan adalah bahasa Mandarin dan bahasa Indonesia. Pengajar memberikan pernyataan meminta tolong pada saat memasuki kelas.

Pada data 7-T7 memperlihatkan bahwa tuturan terjadi antara pengajar dan pemelajar pada saat pengajar memasuki kelas dan lupa menutup kembali pintu yang terbuka, kemudian pengajar meminta tolong pada salah satu mahasiswa bernama Awal untuk menutup kembali pintunya. Tuturan pengajar "bu hao yisi, laoshi lupa tutup pintunya. Awal, neng bang wo guan men ma?." (Maaf, ibu lupa menutup pintunya, Awal, bisa bantu laoshi menutup pintu?) merupakan tindak tutur ekspresif sebagai permintaan tolong dari pengajar. Pemelajar memberikan respon atas tindak tutur tersebut dengan mengucapkan "Hao laoshi" (baik bu) dan kemudain melangkah untuk menutup pintu.

Selanjutnya merupakan pembicaraan antara pengajar dan pemelajar pada saat pemelajar mengerjakan dengan tepat soal yang diberikan oleh pengajar.

\section{Data 8}

Pengajar : “..dui le, Hani mengerjakan dengan tepat. Xiexie ni.”

(...betul, Hani mengerjakan soal dengan tepat. Terima kasih .)

Pemelajar : "Xiexie juga laoshi"

(Terima kasih juga bu.)

\section{Konteks sosiokultural:}

Percakapan terjadi pada mata kuliah Percakapan Mandarin Menengah, tema Review UAS unit 17. Bahasa yang digunakan adalah bahasa Mandarin dan bahasa Indonesia. Pengajar memberikan pernyataan mengucapkan terimakasih kepada pemelajar.

Data 8-T8 memperlihatkan bahwa tuturan pengajar pada saat pembelajaran, bahasa yang mereka gunakan adalah BI dan BM. Tuturan ini terjadi pada saat sesi mengerjakan latihan dengan menulis dan melengkapi huruf Han yang tertera di papan. Tuturan pemelajar “...dui le, Hani mengerjakan dengan tepat. Xiexie ni." (...betul, Hani mengerjakan soal dengan tepat. 
Terima kasih) merupakan jenis tindak tutur ekspresif sebagai ungkapan ekspresi berterimakasih. Dari sebanyak 20 tuturan pengajar, ditemukan sebanyak tiga tindak tutur jenis ekspresif. Tuturan tersebut menggunakan bahasa Mandarin yang sesuai dengan konteks dan kaidah BMn.

\section{Tindak Tutur Deklaratif}

Tindak tutur deklaratif merupakan jenis tindak tutur yang mampu mempengaruhi mitra tutur untuk memahami suatu kondisi yang terjadi dengan menggunakan tuturan. Dalam pembelajaran, pengajar dapat memanfaatkan bentuk tindak tutur direktif dengan pemberian izin, nasihat, perintah, larangan, permintaan, dan pertanyaan.Tindak tutur deklaratif yang dituturkan oleh penutur memiliki tujuan untuk menciptakan hal atau keadaan.

\section{Data 9}

Pemelajar : “... kalau di Zhong Guo barangnya murah-murah ya laoshi?”

(...kalau di Tiongkok barangnya murah-murah ya bu?)

Pengajar : "Ya jelas murah, hen pian yi. Seringnya ada dazhe, diskon."

(Ya jelas murah, sangat murah. Seringnya ada potongan harga, diskon.)

Pemelajar : "Wah mau banget kesana laoshi."

(Wah mau banget kesana bu)

Pengajar : "Ya makanya kalian bisa cari jiang xue jin biar bisa ke Zhong Guo."

(Ya makanya kalian bisa cari beasiswa biar bisa ke Tiongkok)

\section{Konteks sosiokultural:}

Percakapan terjadi pada mata kuliah Percakapan Mandarin Menengah, tema 7 Wo Lai Qing Ke (Aku yang mentraktir). Bahasa yang digunakan adalah bahasa Mandarin dan bahasa Indonesia. Pengajar mendiskusikan teks yang sedang dipelajari dengan topik membeli barang. Pemelajar yang ingin mengetahui bagaimana harga barang di Tiongkok kemudian bertanya kepada pengajar.

Data 9-T9 memperlihatkan bahwa tuturan terjadi pada saat pembelajaran BM dan tuturan terjadi antara pengajar dan pemelajar yang sedang berbicara tentang harga barang di Tiongkok. Pembahasan topik tersebut berkaitan dengan teks yang berada dalam tema 7. Pada data tersebut, pemelajar menanyakan harga barang dan respon yang diberikan oleh mitra tutur yaitu pengajar bersifat memberi informasi. Respon yang dilontarkan oleh pengajar dari pertanyaan pemelajar adalah “"Ya makanya kalian bisa cari jiang xue jin biar bisa ke Zhong Guo.” (Ya makanya kalian bisa cari beasiswa biar bisa ke Tiongkok). Tuturan tersebut mengandung informasi tindak tutur deklaratif karena memiliki informasi tentang harga barang di Tiongkok, dan pengajar memberi nasehat untuk pemelajar agar mencari beasiswa agar bisa pergi ke Tiongkok.

Berikutnya merupakan tindak tutur ilokusi dengan bentuk tindak tutur direktif. Tuturan yang dimaksud dalam data berikut tergolong ke dalam tindak tutur direktif perintah karena 
penutur menyuruh mitra tutur untuk melakukan sesuatu. Pada tuturan jenis ini, penutur dapat menyuruh, memberikan perintah, mengharuskan, memberikan isntruksi, dan memaksa.

\section{Data 10 \\ Pemelajar : : "... hari ini nggak ada tingxie laoshi, berarti buka bab baru ya?” (...hari ini tidak ada dikte ya bu, berarti buka bab baru ya?) \\ Pengajar : "Shei shuo mei tingxie? Setiap minggu pasti ada, kok enak men." (Siapa yang mengatakan tidak ada dikte, kok enak sekali) \\ Pemelajar : "Yah laoshi, belum belajar" \\ (Wah mau banget kesana bu) \\ Pengajar : "Fanzheng women yao tingxie. Qing nimen zhunbei tingxie ben." \\ (Pokoknya kita harus dikte. Silakan kalian siapkan buku diktr)}

\section{Konteks sosiokultural:}

Percakapan terjadi pada mata kuliah Percakapan Mandarin Menengah, tema 5 wo Xiang Xue Taijiquan (Aku ingin belajar Taiji). Bahasa yang digunakan adalah bahasa Mandarin dan bahasa Indonesia. Pengajar mengadakan dikte pada bab ini.

Data 10-T10 menunjukkan bahwa tindak tutur terjadi pada saat pembelajaran dengan penuturnya ialah pengajar, dan lawan tuturnya adalah pemelajar. Tuturan tersebut merupakan terjadi pada saat perkuliahan akan dimulai. Pada setiap perkuliahan, pengajar mengadakan dikte, maka dari itu pengajar memastikan terlebih dahubu agenda dikte dan kemudian memberikan perintah dengan tuturan deklaratif "Fanzheng women yao tingxie. Qing nimen zhunbei tingxie ben.." (Pokoknya kita harus dikte. Silakan kalian siapkan buku dikte). Pada tuturan tersebut mengandung informasi bahwa pengajar menggunakan tindak tutur ilokusi bentuk deklaratif yang ditunjukkan dengan memerintah pemelajar untuk mempersiapkan buku dikte dan segera memulainya. Dari sebanyak 20 tuturan pengajar, ditemukan sebanyak dua tindak tutur jenis deklaratif yang terbagi ke dalam satu tuturan yang berbahasa Indonesia dan satu tuturan berbahasa Mandarin.

\section{SIMPULAN}

Berdasarkan 20 data diatas menunjukkan bahwa dalam proses pembelajaran bahasa Mandarin di prodi D3 Bahasa Mandarin Unsoed terdapat interaksi antara pemelajar dan pengajar. Pada interaksi tersebut terdapat jenis tindak tutur ilokusi yang dituturkan oleh pengajar sebanyak 20 tuturan yang terdiri dari tindak tutur asertif sebanyak 6 data, tindak tutur direktif 3 data, tindak tutur komisif 7 data, tindak tutur ekspresif 3 data, dan tindak tutur deklaratif sebanyak 1 data. Tuturan tersebut dituturkan oelh pengajar dalam kaidah dan konteks BI dan BMn, dengan data yang disampaikan dalam BI sebanyak 8 data dan disampaikan dalam BMn sebanyak 12 data. 
Dari hasil tersebut, pengajar lebih dominan melakukan tindak tutur ilokusi dalam bahasa Mandarin sehingga pemelajar dapat terbiasa dengan ungkapan-ungkapan atau ekspresi yang diungkapkan dalam BMn. Tuturan pengajar sebagai percontohan bagi pemelajar sangat tepat karena pemelajar dapat terbiasa mendengar dan diharapkan kemudian dapat mengaplikasikannya dalam percakapan sehari-hari. Dengan demikian peran pengajar sebagai pendukung dalam perkembangan kemampuan bahasa Mandarin pemelajar dapat terlaksana.

\section{DAFTAR PUSTAKA}

Ardianto. (2013). Tindak Tutur Direktif Guru Dalam Wacana Interaksi Kelas Anak Tunarungu. LITERA: Jurnal Penelitian Bahasa, Sastra, dan Penelitiannya. UNY: Yogyakarta. Vol.12. No.1.

Ariyanti, L. D., \& Zulaiha, I. (2017). Tindak Tutur Ekspresif Humanis Dalam Interaksi Pembelajaran Di Sma Negeri 1 Batang: Analisis Wacana Kelas. Seloka: Jurnal Pendidikan Bahasa dan Sastra Indonesia. UNNES: Semarang. Vol. 6. No. 2.

Austin, J. L. (1962). How To Do Things With Words. London: Oxford University Press.

Cummings, L. (2009). Pragmatik Klinis (diterjemahkan oleh Abdul Syukur Ibrahim, 2010). Yogyakarta: Pustaka Pelajar.

Cummings, L. (1999). Pragmatik, Sebuah Persektif Multidisipliner (diterjemahkan oleh Abdul Syukur Ibrahim. 2007). Yogyakarta: Pustaka Pelajar.

Darwis, A. (2019). Tindak Tutur Direktif Guru Di Lingkungan Smp Negeri 19 Palu: Kajian Pragmatik. Bahasa dan Sastra: Jurnal elektornik Program Studi Bahasa Satra Indonesia dan Daerah, Fakultas Keguruan dan Ilmu Pendidikan, Universitas Tadulako. Universitas Tadaluko: Sulawesi Tengah. Vol. 4. No.2. Hal 21-30.

Etikasari, D. (2012). Tindak Tutur Direktif Dalam Wacana Kelas (Kajian Mikroetnografi Terhadap Bahasa Guru. Jurnal Skripsi. Jurnal Online Universitas Negeri Malang. Malang.

Jumadi. (2010). Wacana: Kajian Kekuasaan berdasarkan Ancangan Etnografi Komunikasi dan Pragmatik. Yogyakarta: Pustaka Prima.

Kentary, A, dkk. (2015). Tindak Tutur Ilokusi Guru Berlatar Belakang Budaya Jawa: Perspektif Gender. HUMANIORA: Jurnal Penelitian. UMS: Surakarta.

Kolamiah, Sri. (2011). “Analisis Tindak Tutur Ilokusi Guru Bahasa Indonesia dalam Interaksi Belajar Mengajar Kelas VII SMP Muhammadiyah 7 Banyudono Boyolali”. Eprints.ums. ac.id. 
Komalasari, I., \& Ramadhani, A. (2017). Tindak Tutur Guru Dan Murid Di Sma Negeri 1 Kelua Kabupaten Tabalong. Stilistika: Jurnal Bahasa, Sastra, dan Pengajarannya. STKIP Banjarmasin: Banjarmasin. Vol. 2. No. 1. Hal. 95-109.

Leech, G. (1993). Prinsip-prinsip Pragmatik (Diterjemahkan oleh: M.D.D. Oka). Jakarta: UIPress.

Mahsun. (2007). Metode Penelitian Bahasa. Jakarta: PT Raja Grafindo Persada.

Megawati, E. (2016). Tindak Tutur Ilokusi pada Interaksi Jual beli di Pasar Induk Kramat jati. Dieksis, 162.

Mey, L. J. (1993). Pragmatics An Introduction . Massachussets: Blackwell Publisher.

Moleong, J. L. (2010). Metodologi Penelitian Kualitatif. Bandung: PT Remaja Rosdakarya.

Muhammad. (2014). Metode Penelitian Bahasa. Yogyakaarta: Ar-Ruz Media.

Prayekti, E. P. (2015). Tindak Tutur Direktif Guru Dalam Pembelajaran Bahasa Indonesia Kelas IX Smp Islam Al Hikmah Jember. Repository UNEJ: Jember.

Purba, Andiopenta. (2011). Tindak Tutur dan Peristiwa Tutur. Pena. 77-91.

Searle, J.R. (1971). The Philosophy of Language. London: Oxford University Press.

Sudaryanto. (2015). Metode dan Teknik Analisis Bahasa. Yogyakarta: Sanata Dharma University Press.

Susmiati, S., dkk. (2013). "Tindak Tutur Ekspresif Guru Terhadap Siswa Dalam Pembelajaran Bahasa Indonesia Kelas VIII Smp Negeri 7 Jember”. Repository UNEJ: Jember.

Yule, G. (1996). Pragmatik. (diterjemahkan oleh Indah Fajar Wahyuni, 2006). Yogyakarta: Pustaka Belajar. 